\title{
PENGARUH PENERAPAN K3, DAN DISIPLIN KERJA TERHADAP PRODUKTIVITAS KARYAWAN PT. ALASKAIR MASPION DI SIDOARJO
}

\author{
Dwi Fita Rahmawati ${ }^{1}$, Untung Lasiyono ${ }^{2}$, Tri Ari Prabowo ${ }^{3}$ \\ Universitas PGRI Adi Buana Surabaya \\ Email : dwifita808@gmail.com
}

Artikel mempunyai tujuan untuk ini menjelaskan sebab persial variabel penerapan $\mathrm{K} 3\left(\mathrm{X}_{1}\right)$ dan disiplin kerja $\left(\mathrm{X}_{2}\right)$ terhadap produktivitas karyawan $(\mathrm{Y})$ pada karyawan PT. Alaskair Maspion di sidoarjo. Penelitian ini memakai penjelasan berjeni pendekatan kuantitatif. Penelian yang kesamaan antar variabel hipotesis yang sudah dirumuskan terlebih dahulu. Populasi diambil karyawan tetap PT. Alaskair maspion di sidoarjo yang sebesar 100 orang. Pengumpulan ini mengambil dua data yaitu kuisioner dan dokumentasi memakai analisis regresi linier berganda dengan metode SPSS 18.00. Hasil penelitian ini menjelaskan bahwa penerapan K3 dan disiplin kerja secara simultan terpengaruh signifikan terhadap produktivitas karyawan.

Kata kunci: Penerapan K3, Disiplin Kerja, Produktivitas Karyawan.

\section{ABSTRACT}

The article has the purpose of this to explain the persial cause of the variable $K 3\left(X_{1}\right)$ and work discipline $\left(\mathrm{X}_{2}\right)$ on employee productivity $(Y)$ on the employees of PT. Alaskair Maspion di sidoarjo. The research id using the explanation of the manifold a quantitative approach. Explanatory research is a research that explains the similarities between variables and evaluates hypotheses that have been formulated in advance. The taken permanent PT Alaskair Maspion in Sidoarjo, amounting to 100 people. This collection takes the two data, namely quesinnaires and documentation wear analysis regreasi linear regression method with SPSS 18.00. The results of this study explain that the simultaneous application of $\mathrm{K} 3$ and work discipline is significantly affected on employee productivity. Keyword: Implementation K3, work discipline, employee productivity.

\section{PENDAHULUAN}

SDM ialah salah satu faktor penting dari suatu perusahaan, dalam manajemen sumber karyawan maupun seluruh pegawai dalam perusahaan sebagai salah satu kunci utama yang penting untuk meraih keberhasilan satu tujuan, maka dari itu K3 dan disiplin kerja sangat penting, jika tidak adanya perlindungan K3 maupun kedisiplinan tersebut karyawan merasa rugi oleh perusahaan dan karyawan tidak mendapatkan perlindungan terhadap perusahaan tersebut. Oleh sebab itu untuk mencapai kesuksesan dan keberhasilan perusahaan maka diperlukan suatu pedoman perlindungan dan tata tertib sebagai usaha agar mendapat hasil kerja yang memuaskan, perusahaan untung karyawanpun juga untung.

Penelitian ini terbagi menjadi tiga variabel bebas yaitu pengarun penerapan K3 (X1), disiplin kerja (X2), produktivitas karyawan (Y). perlindungan yang baik adanya lingkungan kerja yang aman 
sebab akan memunculkan kenyamanan untuk bekerja dengan semangat. Semakin adannya fasilitas keselamatan dan kesehatan kerja dan mentaati kedisiplinan semakin sedikit terjadinya kecelakaan kerja maupun tegoran untuk karyawan.

Pada penelitian ini ditentukan 5 faktor keselamatan kerja yaitu : pengawasan dan disiplin, pelatihan keselamatan, kontrol lingkungan kerja, penerapan keselamatan kerja, serta peningkatan kesadaran K3. kemudian produktivitas kerja bisa ditentukan dari hal-hal yang menyebabkan produktivitas kerja karyawan dalam bentuk kemampuan bekerja.

K3 dan disiplin kerja djadikan untuk aspek melindungi tenaga kerja maupun peraturan perusahaan guna untuk melindungi aset perusahaan dan mengatur sistem kerja karyawan untuk memberikan jaminan kondisi aman dan sehat pada saat pelaksanaan pekerjaan K3. serta disiplin kerja mempunyai tujuan untuk mengurangi angka kecelakaan kerja yang ada di indonesia.

\section{Rumusan Masalah}

1. Apakah Penerapan program (K3) pengaruh pada produktivitas karyawan PT. Alaskair maspion di sidoarjo?

2. Apakah Disiplin Kerja pengaruh terhadap produktivitas karyawan PT. Alaskair maspion di sidoarjo?

3. Apakah Penerapan (K3), Disiplin Kerja pengaruh secara simultan terhadap produktivitas karyawan pada PT. Alaskair Maspion di sidoarjo?

\section{Tujuan Penelitian}

1. Agar bisa menganalisis pengaruh penerapan K3 terhadap produktivitas karyawan PT. Alaskair Maspion di Sidoarjo.

2. Agar bisa menganalisis pengaruh Disiplin Kerja terhadap produktivitas karyawan PT. Alaskair Maspion di Sidoarjo.

3. Agar bisa dan menganalisis pengaruh penerapan K3 dan Disiplin Kerja terhadap produktivitas karyawan PT. Alaskair Maspion di Sidoarjo.

\section{Landasan Teori}

Pengertian K3 untuk melindung dan mengamankan tenaga kerja baik fisik maupun mentalagarbisamemaksimalkan pekerjaansesuaitarget perisahaan.

Indikato K3 ada 7 berikut ini :

1. Lingkungan perusahaan

2. Tempat kerja

3. Pelayanan kesehatan

4. Wewenang pekerjaan

5. Peralatan keamanan (safety)

6. Kelalaian

7. Pembiayaan kesehatan 
Dalam perusahan wajib menegakkan yang namanya disiplin kerja bagi karyawan agar kompetensi kerja seseorang tekun secara berkelanjutan dan melakukan pekerjaan dengan prosedur dan peraturan berlaku yang sudah ditentukan. Indikator yang mempengaruhi sebanyak 8 ialah:

1. Harapan dan keahlian

2. Taat kepada pimpinan

3. Upah gaji dan kesejahteraan

4. Tidak memandang yang lemah

5. Pengawasan ketat

6. Sanksi

7. Disiplin

8. Bersosialisasi dengan sesama

Produktivitas kerja merupakan sesuatu yang harus dilakukan secara efektif dan efesien dalam target tujuan yang telah ditentukan.Sehingga dibutuhkan untuk mencapai keberhasilan ditentukan dengan cara diukur produktivitas kerja, diantaranya ada 6 indikator sebagai berikut:

1. Keahlian

2. Mencapai tujuan

3. Semangat

4. Pengembangan diri

5. Bermutu

6. Efisien

\section{Kerangka Konseptual}

Adanya kerangka konseptual, akan mempermudah peneliti dalam mengarahkan penelitian sesuai dengan apa yang diinginkan oleh peneliti. Berikut adalah kerangka konseptual yang akan digunakan peneliti sebagai penelitian :

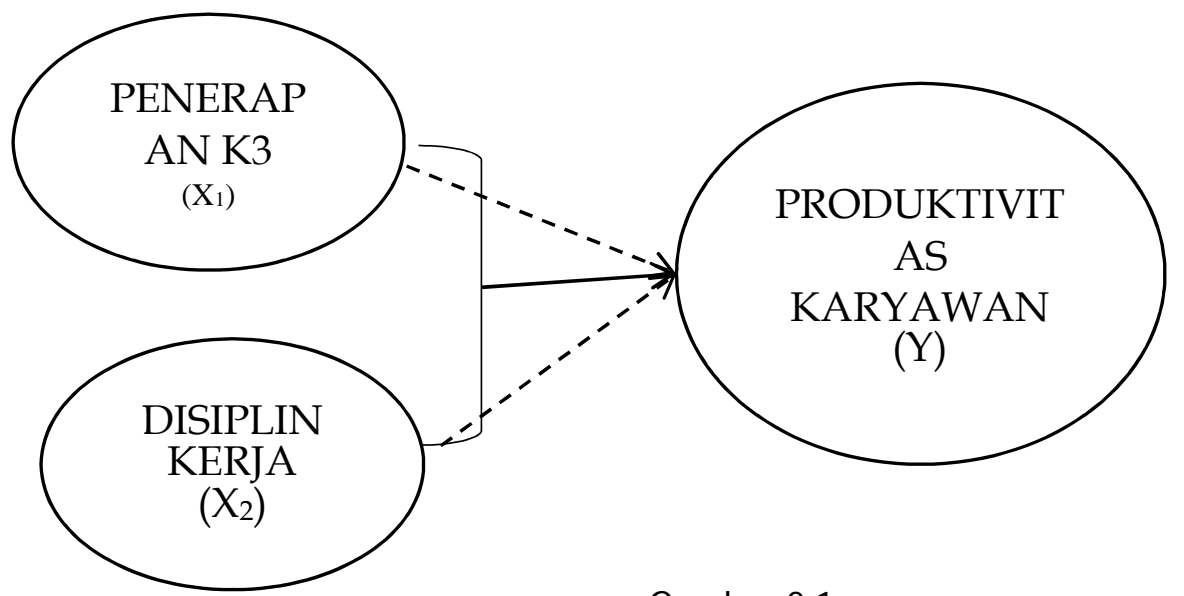

Gambar 2.1 


\section{Kerangka Konseptual}

\section{Hipotesis}

H1 : Penerapan K3 berpengaruh terhadap produktivitas karyawan pada PT. Alaskair Maspion di Sidoarjo

H2: $\quad$ Disiplin Kerja berpengaruh terhadap produktivitas karyawan pada PT. Alaskair Maspion di Sidoarjo.

H3: $\quad$ Penerapan K3 dan Disiplin Kerja berpengaruh terhadap produktivitas karyawan pada PT.Alaskair Maspion di Sidoarjo.

\section{Populasi dan Sampel}

Populasi yang saya teliti ada 100 karyawan tetap dalam perusahaan PT. Alaskair Maspion di sidoarjo, adapun sampel untuk penelitian ini menggunakan cluster sampling, berjumlah 100 orang.

\section{Teknik Pengumpulan Data}

Penelitian saya ada dua data yaitu pengumpulankuisioner dan dokumentasi. Kuisioner ialah suatu keahlian mengumpulkan data menggunkan metode yang mempunyai pertanyaan yang ditulis oleh responden, misalnya sejumlah kuis

digunakan untuk memperoleh informasi, sedangakn dokumentasi digunakan untuk mengambil data sekunder seperti organisasi, job deskrisi, visi dan misi, tujuan perusahaan dan juga sebagai bahan pelengkap untuk materi yang sedang diteliti olrh peneliti.

\section{Analisis Data}

1. Instrumen Penelitian

a. Uji Validitas

b. Uji Reliabilitas

2. Uji Asumsi Klasik

a. Uji Normalitas

b. Uji Multikolinearitas

c. Uji Heteroskedastitas

\section{Hasil Penelitian}

\section{Hasil Uji Validitas Pengaruh Penerapan K3}

\begin{tabular}{cccc}
\hline Item & $\begin{array}{c}\mathbf{r} \\
\text { hitung }\end{array}$ & $\begin{array}{c}\mathbf{r} \\
\text { tabel }\end{array}$ & $\begin{array}{c}\text { Keteranga } \\
\mathbf{n}\end{array}$ \\
\hline $\mathbf{1}$ & 0,453 & 0,196 & Valid \\
$\mathbf{2}$ & 0,374 & 0,196 & Valid
\end{tabular}




\begin{tabular}{|c|c|c|c|c|}
\hline 3 & 0,383 & 0,196 & Valid & \\
\hline 4 & 0,440 & 0,196 & Valid & \\
\hline 5 & 0,315 & 0,196 & Valid & \\
\hline 6 & 0,464 & 0,196 & Valid & \\
\hline 7 & 0,517 & 0,196 & Valid & \\
\hline 8 & 0,357 & 0,196 & Valid & \\
\hline 9 & 0,368 & 0,196 & Valid & Sumber: Lampiran Output \\
\hline 10 & 0,479 & 0,196 & Valid & Menunjukkan hasil dari \\
\hline 11 & 0,336 & 0,196 & Valid & uji validitas variabel Pengaruh \\
\hline 12 & 0,345 & 0,196 & Valid & Penerapan K3 $\left(\mathrm{X}_{1}\right)$ mempunyai \\
\hline
\end{tabular}

pertanyaan karena nilai $r$ hitung pada item memiliki nilai lebih besar dari $r$ table pada taraf signifikasi $5 \%$ yakni sebesar 0,196 . Berdasarkan hasil uji validitas diatas dapat dikatakan bahwa item pertanyaan dalam kuisioner variabel Pengaruh Penerapan K3 dapat dipercaya dalam mengambil data penelitan.

Hasil Uji Validitas Disiplin Kerja

\begin{tabular}{cccc}
\hline Item & $\begin{array}{c}\mathrm{r} \\
\text { hitung }\end{array}$ & r tabel & Keterangan \\
\hline $\mathbf{1}$ & 0,495 & 0,196 & Valid \\
$\mathbf{2}$ & 0,513 & 0,196 & Valid \\
$\mathbf{3}$ & 0,540 & 0,196 & Valid \\
$\mathbf{4}$ & 0,665 & 0,196 & Valid \\
$\mathbf{5}$ & 0,547 & 0,196 & Valid \\
$\mathbf{6}$ & 0,740 & 0,196 & Valid \\
$\mathbf{7}$ & 0,663 & 0,196 & Valid \\
$\mathbf{8}$ & 0,606 & 0,196 & Valid \\
$\mathbf{9}$ & 0,588 & 0,196 & Valid \\
\hline
\end{tabular}

Sumber: Lampiran Output SPSS 18, Data Diolah Tabel menunjukkan hasil dari uji validitas variabel Disiplin Kerja $\quad\left(\mathrm{X}_{2}\right)$ mempunyai kriteria valid untuk semua item pertanyaan karena nilai r hitung pada item memiliki nilai lebih besar dari $r$ table pada taraf signifikasi 5\% yakni sebesar $\quad 0,196$. Berdasarkan hasil uji validitas diatas dapat dikatakan bahwa item 
pertanyaan dalam kuisioner variabel Disiplin Kerja dapat dipercaya dalam mengambil data penelitian.

Hasil Uji Validitas Produktivitas Karyawan

\begin{tabular}{cccc}
\hline Item & r hitung & r tabel & Keterangan \\
\hline $\mathbf{1}$ & 0,519 & 0,196 & Valid \\
$\mathbf{2}$ & 0,591 & 0,196 & Valid \\
$\mathbf{3}$ & 0,714 & 0,196 & Valid \\
$\mathbf{4}$ & 0,624 & 0,196 & Valid \\
$\mathbf{5}$ & 0,657 & 0,196 & Valid \\
$\mathbf{6}$ & 0,605 & 0,196 & Valid \\
$\mathbf{7}$ & 0,690 & 0,196 & Valid \\
$\mathbf{8}$ & 0,572 & 0,196 & Valid \\
$\mathbf{9}$ & 0,665 & 0,196 & Valid \\
\hline
\end{tabular}

Sumber: Lampiran Output SPSS 18, Data Diolah

Tabel menunjukkan hasil dari uji validitas variabel Produktivitas Karyawan $(Y)$ mempunyai kriteria valid untuk semua item pertanyaan karena nilai $r$ hitung pada item memiliki nilai lebih besar dari $r$ table pada taraf signifikasi 5\% yakni sebesar 0,196. Berdasarkan hasil uji validitas diatas dapat dikatakan bahwa item pertanyaan dalam kuisioner variabel Produktivitas Karyawan dapat dipercaya dalam mengambil data penelitian.

\begin{tabular}{ccc} 
Y & $\begin{array}{c}\text { Hasil Uji Reliabilitas Semua VariabSumber } \\
\text { Reliabel }\end{array}$ \\
\hline Item & $\begin{array}{c}\text { Cronbac } \\
\text { h Alpha }\end{array}$ & $\begin{array}{c}\text { Keteranga } \\
\text { n }\end{array}$ \\
\hline & & 352
\end{tabular}


Vol. 1 No. 1 Desember 2020

\begin{tabular}{ccc}
\hline $\mathbf{X 1}$ & 0,769 & Reliabel \\
$\mathbf{X} 2$ & 0,865 & Reliabel \\
$\mathbf{Y}$ & 0,881 & Reliabel \\
\hline
\end{tabular}

Sebuah instrumen dapat dinyatakan reliable jika memiliki nilai koefisien Cronbach Alpha lebih besar dari 0,60. Berdasarkan hasil uji reliabilitas di atas, keseluruhan variabel dalam penelitian ini memiliki nilai Cronbach Alpha lebih besar 0,60 yang berarti bahwa semua variabel dalam penelitian ini dapat dinayatan reliabel.

Hasil Uji Normalitas

Unstandardized Residual

\begin{tabular}{llr}
\hline $\mathrm{N}$ & & 100 \\
Normal Parameters ${ }^{\mathrm{a}} \mathrm{b}$ & Mean & .0000000 \\
& Std. & 2.08861007 \\
& Deviation & \\
Most Extreme & Absolute & .091 \\
Differences & Positive & .055 \\
& Negative & -.091 \\
Kolmogorov-Smirnov Z & & .915 \\
Asymp. Sig. (2-tailed) & & .372 \\
\hline
\end{tabular}

Berdasarkan hasil uji normalitas pada tabel di atas diketahui nilai Asymp. Sig. (2-tailed) sebesar 0,130>0,05 maka dapat dikatakan data dalam penelitian ini berdistribusi Normal.

\section{Hasil uji Multikolonearitas}

Model

Collinearity Statistics 


\begin{tabular}{llrl} 
& & Tolerance & \multicolumn{1}{l}{ VIF } \\
\hline $1 \quad \begin{array}{l}\text { (Constant) } \\
\text { Penerapan }\end{array}$ & .629 & 1.591 \\
K3 & & \\
Disiplin & .629 & 1.591 \\
Kerja & & \\
\hline
\end{tabular}

Sumber: Lampiran Output SPSS 18, Data Diolah

Berdasarkan hasil analisis multikolinearitas pada tabel diketahui nilai Tolerance pada masing-masing variabel $>$ 0,10 dan nilai vif $<10$ maka dapat dikatakan tidak terjadi multikolinearitas atau tidak ada kesamaan antar variabel bebas.

\section{Hasil Uji Heterokedastistas}

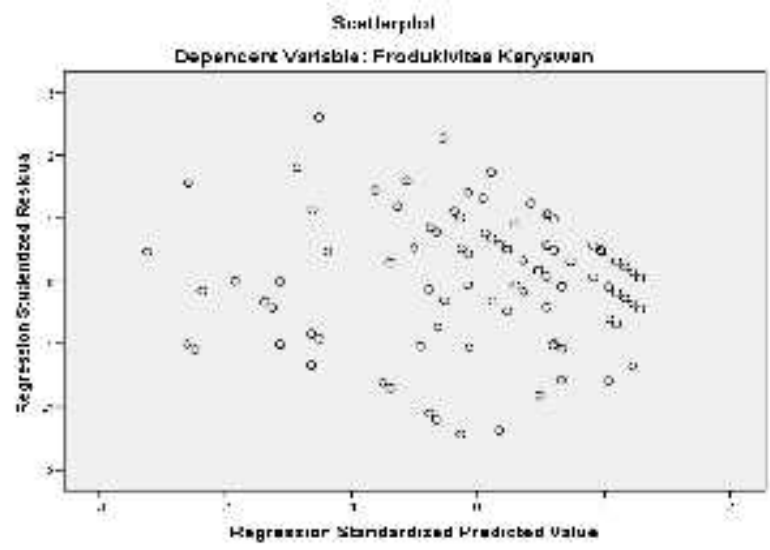

\section{Gambar 4.1 Scatterplott}

\section{Hasil Uji Autokorelasi}




\begin{tabular}{|c|c|c|c|c|c|}
\hline \multirow[t]{2}{*}{ Model } & & & Adjusted R & d. Error of the & Durbin- \\
\hline & $\mathrm{R}$ & R Square & Square & Estimate & Watson \\
\hline 1 & $.807 a$ & .651 & .644 & 2.04540 & 1.517 \\
\hline
\end{tabular}

a. Predictors (Constant) : Penerapan K3, Disiplin Kerja

b. Dependent Variable : Produktivitas Karyawan

Berdasarkan hasil analisis pada table 4.19 nilai durbin Watson sebesar 1,517, jumlah sampel 100 (n), dan jumlah variable independen $2(k=2)$, maka ditabel durbin Watson akan didapat nilai du sebesar 1.65. karena nilai DW 1,517 lebih besar dari batas atas (du 1,65 dan kurang 4-1.65 (2,35), maka dapat disimpulkan bahwa tidak terdapat autokorelasi.

Hasil Uji Analisis Regresi Linier Berganda

\begin{tabular}{|c|c|c|c|c|c|c|c|c|}
\hline & Model & & & $\begin{array}{l}\text { Standa } \\
\text { dized }\end{array}$ & & & & \\
\hline & & Unsta & ndardized & Coeffic & & & & \\
\hline & & $\mathrm{COE}$ & Ificients & ents & & & Collinearit & Statistics \\
\hline & & B & Std. Error & Beta & $\mathrm{t}$ & Sig. & Tolerance & VIF \\
\hline 1 & (Constant) & 3.725 & 3.155 & & 1.181 & .241 & & \\
\hline & Penerapan & .175 & .070 & .189 & 2.504 & .014 & .629 & 1.591 \\
\hline & K3 & & & & & & & \\
\hline & Disiplin & .681 & .076 & .677 & 8.947 & .000 & .629 & 1.591 \\
\hline & Kerja & & & & & & & \\
\hline
\end{tabular}

Berdasarkan hasil uji statistik regresi berganda pada tabel 4.20 dapat dirumuskan dengan persamaan regresi linier berganda sebagai berikut: 


$$
\begin{aligned}
& Y=\alpha+\beta 1 X 1+\beta 2 X 2+e \\
& Y=3,725+0,175 X 1+0,681 X 2+e
\end{aligned}
$$

Berdasarkan persamaan regresi linier diatas dapat diketahui informasi sebagai berikut:

a. Nilai kontanta ( $\alpha$ ) adalah 3,725 yang berarti bahwa Pengaruh Penerapan K3, dan Disiplin Kerja bernilai 0 maka Persepsi mengenai Produktivitas Karyawan bernilai positif yaitu 3,725.

b. Nilai koefisien regresi ( $\beta$ ) variabel Penerapan $\mathrm{K} 3\left(\mathrm{X}_{1}\right)$ bernilai positif yaitu 0,175 hal tersebut menyatakan bahwa setiap variabel Pengaruh Penerapan K3 mengalami kenaikan sebesar $1 \%$ maka persepsi mengenai Produktivitas Karyawan akan meningkat sebesar 17,5\%.

c. Nilai koefisien regresi $(\beta)$ variabel Disiplin Kerja $\left(X_{2}\right)$ bernilai positif yaitu 0,681 hal tersebut menyatakan bahwa setiap variabel Disiplin Kerja mengalami kenaikan sebesar $1 \%$ maka persepsi mengenai Produktivitas karyawan akan meningkat sebesar $68,1 \%$.

\begin{tabular}{|c|c|c|c|c|c|}
\hline \multirow[t]{2}{*}{ Model } & & & Adjusted R & Std. Error of the & Durbin- \\
\hline & $\mathrm{R}$ & R Square & Square & Estimate & Watson \\
\hline 1 & $.807^{a}$ & .651 & .64 & 2.04540 & 1.517 \\
\hline
\end{tabular}

\section{Hasil Analisis Koefisien Korelasi}

Sumber: Lampiran Output SPSS 18, Data Diolah

Berdasarkan hasil uji analisis koefisien korelasi pada tabel di dapat informasi bahwa nilai koefisien korelasi sebesar 0,807 . Nilai tersebut berada pada level interval koefisien $0,600 \mathrm{~s} / \mathrm{d} 0,799$ yang menunjukkan tingkat hubungan yang kuat sesuai pedoman Sugiyono, 2012.

\begin{tabular}{|c|c|c|c|c|c|c|}
\hline \multirow{2}{*}{\multicolumn{2}{|c|}{ Model }} & \multicolumn{2}{|c|}{$\begin{array}{l}\text { Unstandardized } \\
\text { Coefficients }\end{array}$} & \multicolumn{3}{|l|}{$\begin{array}{c}\text { Standardized } \\
\text { Coefficients }\end{array}$} \\
\hline & & B & Std. Error & Beta & $t$ & Sig. \\
\hline \multirow[t]{3}{*}{1} & (Constant) & 3.725 & 3.155 & & 1.181 & .241 \\
\hline & $\begin{array}{l}\text { Penerapa } \\
\text { n K3 }\end{array}$ & .175 & .070 & 189 & 2.504 & .014 \\
\hline & $\begin{array}{l}\text { Disiplin } \\
\text { Kerja }\end{array}$ & 681 & .076 & .677 & 8.947 & .000 \\
\hline
\end{tabular}

\section{Hasil Uji t}

Sumber: Lampiran Output SPSS 18, Data Diolah 
Diketahui nilai t tabel dari jumlah responden 100 yaitu sebesar 1,983. Berdasarkan hasil output pada tabel 4.21 dapat diketahui bahwa :

a. Pada variabel Penerapan K3 (X1) diperoleh nilai t-hitung 2,504 $>$ t-tabel $=1,983$ dengan tingkat signifikansi 0,014<0,05. Dari hasil tersebut maka dapat dinyatakan hipotesis diterima. Yang artinya Penerapan K3 (X1) berpengaruh signifikan dan positif terhadap Produktivitas Karyawan (Y).

b. Variabel Disiplin Kerja (X2) diperoleh t-hitung 8,947 > t-tabel $=1,983$ dengan tingkat signifikansi $0,014<0,05$. Dari hasil tersebut maka dapat dinyatakan hipotesis diterima. Yang artinya Disiplin Kerja (X2) berpengaruh signifikan dan positif terhadap Produktivitas Karyawan (Y).

\section{Hasil Uji Simultan (Uji F)}

\begin{tabular}{rlrrrrr}
\hline & Model & \multicolumn{1}{c}{$\begin{array}{c}\text { Sum of } \\
\text { Squares }\end{array}$} & $\begin{array}{c}\text { D } \\
\mathrm{f}\end{array}$ & Mean Square & F & Sig. \\
\hline 1 & Regression & 756.296 & 2 & 378.148 & 90.387 & $.000^{\mathrm{a}}$ \\
& Residual & 405.814 & 97 & 4.184 & & \\
& Total & 1162.110 & 99 & & & \\
\hline
\end{tabular}

Sumber: Lampiran Output SPSS 18, Data Diolah

Tabel menunjukkan bahwa nilai Fhitung sebesar 90,387 > Ftabel $(0,05)$ sebesar 2,78 dan juga nilai dari P-value sebesar $0,000<\alpha(0,05)$ sehingga didapatkan keputusan Ho ditolak dan Ha diterima yang berarti variabel Penerapan K3 (X1), Disiplin Kerja (X2), berpengaruh secara simultan terhadap Produktivitas Karyawan (Y).

\section{Pembahasan}

\section{Pengaruh Penerapan K3 Terhadap Produktivitas Karyawan}

Dari hasil pengujian hipotesis pertama $\left(\mathrm{H}_{1}\right)$ menggunakan uji t yang bertujuan untuk melihat pengaruh secara persial, Berdasarkan tabel 4.23 diperoleh nilai t hitung variabel pengaruh peneran K3 terhadap Produktivitas Karyawan 2,504 dan diketahui signifikan variabel pengaruh penerapan K3 sebesar 0,0014 < 0,05. hal ini berarti hipotesis menyatakan bahwa variabel pengaruh penerapn $\mathrm{K} 3$ berpengaruh terhadap produktivitas karyawan.

Hasil dalam penelitian sejalan dengan penelitian yang dilakukan oleh Fatoni (2018) yang berjudul "Pengaruh Keselamatan Dan Kesehatan Kerja (K3) Terhadap Kinerja Karyawan di PG kebon Agung Malang". bahwa pengaruh penerapan K3 memiliki hubungan yang positif dan berpengaruh signifikan terhadap keinginan karyawan sehingga adanya kenyamanan serta kenyamanan sumber daya manusia dalam bekerja setiap karyawan memiliki hak atas perlindungan keselamatannya di dalam lingkungan kerjanya. Hal ini sesuai dengan pendapat Sunyoto (2012)

Berdasarkan hasil penelitian diatas diketahui penerapan k3 berpengaruh terhadap produktivitas karyawan hal ini karena karyawan merasa pentingnya penerapan k3 di tempat kerja untuk menyelesaikan suatu pekerjaan agar efektif dan efesien. Hal ini sejalan dengan teori yang dikemukan oleh Mangkunegara (2011:161) menyatakan "Program kesehatan kerja menunjukkan pada kondisi yang bebas dari gangguan fisik, mental, emosi atau rasa sakit yang 
disebabkan oleh lingkungan kerja". Resiko kesehatan merupakan faktor-faktor dalam lingkungan kerja yang bekerja melebihi periode waktu yang ditentukan, lingkungan yang dapat membuat stres emosi atau gangguan fisik.

\section{Pengaruh Disiplin Kerja Terhadap Produktivitas Karyawan}

Pada pengujian hipotesis kedua $\left(\mathrm{H}_{2}\right)$ dengan menggunakan uji t yang diperoleh nilai t hitung variabel Disiplin Kerja terhadap Produktivitas Karyawan PT. Alaskair Maspion di Sidoarjo sebesar 8,947 dengan nilai signifikan sebesar 0,014<0,05. hal ini berarti hipotesis menyatakan variabel Disiplin Kerja berpengaruh signifikan terhadap Produktivitas Karyawan.

Hasil penelitian ini sejalan dengan pendapat Setiawan (2013) dengan judul " Pengaruh Disiplin Kerja Dan Motivasi Terhadap Kinerja Karyawan Pada Rumah Sakit Umum Daerah Kanjuruhan Malang". hasil dalam penelitian menyatakan bahwa Disiplin kerja mempengaruhi Produktivitas Karyawan, dikarenakan perusahaan tidak bisa berjalan jika tidak adanya kedisiplinan bagi karyawan. Hal ini sesuai dengan pendapat Hasibu (2010)

Dari hasil penelitian diketahui Disiplin Kerja berpengaruh signifikan terhadap Produktivitas Karyawan hal ini karena karyawan merasa dengan adanya aturan yang diterpakan perusahaan sudah cukup baik untuk menjaga konsistensi kerja karyawan dan menjaga standar kerja pada perusahaan. Hal ini sejalan dengan teori yang dikemukan oleh menurut Sinambela (2017:335), berikut pengertiannya: Disiplin kerja adalah kemampuan kerja seseorang untuk secara teratur, tekun secara terus menerus dan bekerja sesuai dengan aturan-aturan berlaku dengan tidak melanggar aturan-aturan yang sudah ditetapkan.

\section{Pengaruh Penerapan K3 dan disiplin Kerja Terhadap Produktivitas Karyawan}

Berdasarkan hasil uji F menunjukkan bahwa nilai Fhitung sebesar 90,387 > Ftabel $(0,05)$ sebesar 2,78 dan juga nilai dari P-value sebesar $0,000<a(0,05)$ sehingga didapatkan keputusan tolak $\mathrm{HO}$ yang berarti minimal ada pengaruh yang signifikan antara variabel Penerapan K3 (X1), Disiplin Kerja (X2), terhadap Produktivitas Karyawan (Y). hal ini karena karyawan merasa penerapan k3 dan aturan yang diterapkan pada perusahaan sudah cukup baik hal ini dapat dilihat dari jawaban responden pada masing-masing pernyataan di tiap-tiap item pernyataan dimana sebagaian besar responden menjawab setuju.

$\mathrm{Hal}$ ini sejalan dengan teori yang dikemukan oleh Moenir (2007:207), "Kesehatan kerja adalah suatu usaha dan keadaan yang memungkinkan seseorang mempertahankan kondisi kesehatannya dalam pekerjaan" dan Sinambela (2017:335) Disiplin kerja adalah kemampuan kerja seseorang untuk secara teratur tekun secara terus menerus dan bekerja sesuai dengan anturan-aturan berlaku dengan tidak melanggar aturan-aturan yang sudah ditetapkan. Jadi disiplin yang baik menunjukkan besarnya rasa tanggung jawab seseorang terhadap tugas-tugas yang diberikan kepadannya. Hal ini mendorong adanya gairah kerja, semangat bekerja dan terwujudnya tujuan perusahaan, karyawan dan masyarakat.

\section{Kesimpulan}

Berdasarkan hasil analisis data pada bab sebelumnya maka kesimpulan pada peneliti ini adalah sebagai berikut:

1. Pengaruh Penerapan K3 berpengaruh signifikan terhadap Produktivitas Karyawan, yang berarti Ha diterima, hal ini dibuktikan dengan uji t dengan nilai t-hitung 2,504 > t-tabel = 1,983 dengan tingkat signifikansi 0,014<0,05.. 
2. Disiplin Kerja berpengaruh terhadap Produktivitas Karyawan, yang berarti Ha diterima. hal ini dibuktikan dengan uji t diperoleh t-hitung 8,947 > t-tabel = 1,983 dengan tingkat signifikansi 0,014 $<0,05$

Penerapan K3 dan Disiplin Kerja berpengaruh secara simultan terhadap Produktivitas Karyawan. yang berarti Ha diterima, Hal ini dibuktikan dengan uji $t$ dengan nilai bahwa nilai $\mathrm{F}$ hitung sebesar $90,387>$ Ftabel $(0,05)$ sebesar 2,78 dan juga nilai dari P-value sebesar $0,000<\alpha(0,05)$ dengan nilai signifikan 0,014 $<0,05$.

\section{Saran}

Berdasarkan hasil dari kesimpulan pada penelitian ini, maka dapat diberikan saran sebagai berikut:

1. Disarankan kepada pihak pimpinan PT. Alaskair Maspion sebaiknya meningkatkan frekuensi pelatihan keselamatan dan kesehatan kerja (K3) bagi karyawan sudah dilakukan oleh PT. Alaskair Maspion, tetapi hanya setahun sekali saja. Pelatihan keselamatan dan kesehatan kerja sebaiknya diadakan dalam satu bulan sekali lebih baik. Pelatihan bertujuan bertujuan untuk menekan pada segi-segi bahaya atau resiko suatu pekerjaan, aturan keselamatan dan kesehatan kerja dan kondisi kerja yang aman

2. Disarankan kepada pihak pimpinan perusahaan agar mencapai tujuan yang diinginkan instansi harus tetap menjaga atau mempertahankan kedisiplinan kerja para karyawan serta meningkatkannya lagi walaupun disiplin kerja tidak ada pengaruhnya terhadap kinerja karyawan. Dengan cara menegur atau sampai memberi sanksi pada karyawan yang melanggar aturan yang ada sesuai tingkat kesalahannya serta memberikan reward atau pengakuan jika karyawan tersebut menjadi karyawan yang teladan.

3. Bagi peneliti selanutnya yang mengambil penelitian sama dengan penelitian ini, disarankan untuk menambah variabel independen lain yang memiliki keterkaitan dengan pengaruh K3 (keselamatan dan kesehatan kerja) dalam perusahaan.

4. Penelitian selanjutnya sebaiknya menggunakan sampel yang lebih luas, karena penelitian ini pada lingkup yang masih sempit yakni hanya karyawan tetap yang saya ambil sampelnya sedangankan di perusahaan maspion terdapat banyak beberapa pegawai seperti staff, karyawan tetap, dan karyawan orsosing. 


\section{DAFTAR PUSTAKA}

Agatha, Djudi, Yuniadi, 2018. Pengaruh Keselamatan dan Kesehatan Kerja (K3) Terhadap Kinerja Karyawan (Studi Pada PG Kebon Agung Malang). Administrasi Bisnis (JAB), $\quad$ Volume. 56, Nomer 1 maret 2018.

Bangun, Wilson. 2012, Manajemen Sumber Daya Manusia. Bandung: Erlangga

Cahya, Risna. 2015. Pengaruh Keselamatan dan Kesehatan Kerja Terhadap Kinerja Karyawan (Studi pada Karyawan Bagian Pabrikasi PT Pabrik Gula Krebet Baru～Malang). Skripsi Fakultas Ilmu Administrasi. Universitas Brawijaya.

Fajar, Heru. 2010. Manajemen Sumber Daya Manusia Sebagai Dasar Meraih Keunggulan Bersaing. UPP STIM YKPN. Yogyakarta

Ghozali, Imam. 2011, Aplikasi Analisis Multivariate dengan $\quad$ Program IBM SPSS 18. Semarang: Badan Penerbit Universitas Diponegoro.

Haerani, Rizkya. 2014. pengaruh Keselamatan dan Kesehatan Kerja terhadap Kinerja Karyawan (Studi pada Karyawan Tetap PT Perkebunan Nusantara X Persero) PG Toelangan Sidoarjo). Skripsi Fakultas ILmu Administrasi. Universitas Brawijaya.

Harlie, M. Pengaruh Disiplin Kerja, Motivasi dan Pengembangan Karier Terhadap Kinerja Pegawai Negeri Sipil Pada Pemerintahan Kabupaten Tabalong di Tanjung Kalimantan Selatan. Jurnal Manajemen dan Akuntansi 11 (2): 10-23.

Hasibuan, Malayu S. P. 2013. Manajemen Sumber Daya Manusia. Jakarta: PT. Bumi Aksara Hermawan, Amirullah, 2015 Metode Penelitian Bisnis. Malang: Penerbit Media Nusa Creative. Holil, Muhammad dan Sriyanto, Agus. 2010. pengaruh Motivasi danDisiplin Kerja Terhadap Kinerja

Pegawai (Studi Kasus Kantor Pelayanan Pajak Badan Usaha Milik Negara), Jurnal Manajemen 5 (1): 22-38.

Ilfani, 2013. Analisis Pengaruh Keselamatan dan Kesehatan Kerja Terhadap Kinerja Karyawan (Studi Pada PT. Apac Inti Corpora Bawen Jawa Tengah Unit Spinning 2). Skripsi Fakultas Ekonomi dan Bisnis Universitas Diponegoro.

Mangkunegara, 2004, Evaluasi Kinerja SDM. Refika Aditama. Bandung.

Bandung.

Piran, 2018. Pengaruh Keselamatan dan Kesehatan Kerja (K3), Lingkungan Kerja Fisik dan Non

Fisik Terhadap Produktivitas Karyawan di PTPN X KREMBOONG SIDOARJO.Skripsi Fakultas Ekonomi Universitas PGRI Adi Buana Surabaya

Rahmana, 2018. Pengaruh Disiplin Kerja Dan Lingkungan Kerja Terhadap Produktivitas Kerja Karyawan PT. KERTA RAJASA RAYA TROPODO DI SIDOARJO. Skripsi Fakultas Ekonomi Universitas PGRI Adi Buana Surabaya.

Setiawan, 2013. Pengaruh Disiplin Kerja Dan Motivasi Terhadap Kinerja Karyawan Pada Rumah Sakit Umum Daerah Kanjuruhan Malang. Jurnal IImu Manajemen, Volume 1, Nomor 4 Juli 2013.

Sinambela, Lijan Poltak. 2016 Manajemen Sumber Daya Manusia, PT. Bumi Aksara, Jakarta 
Suma'mur. 2001. Keselamatan Kerja dan Pencegahan Kecelakaan, jakarta: CV Haji Masagung. Sunyoto, 2013. Manajemen Sumber Daya Manusia. Penerbit CAPS. Yogyakarta.

Sugiyono. 2014. Metode Penelitian Pendidikan Pendekatan Kuantitatif, Kualitatif, $\quad$ dan $\quad R \& D$. Bandung: Alfabeta 